\title{
Información y Triage: Puntos clave frente a la pandemia de la Gripe A
}

\begin{abstract}
La aparición del brote de gripe por el virus influenza A (H1N1) representa un nuevo reto para la capacidad de adaptación y respuesta de los diferentes Sistemas Sanitarios. La Organización Mundial de la Salud (OMS) activó su dispositivo de emergencia a nivel global el 24 de abril de 2009, lo que ha estimulado el contacto permanente entre países, instituciones y autoridades sanitarias de todo el mundo para coordinar sus actuaciones. El 11 de junio de 2009 la OMS elevó el nivel de alerta al establecer la situación de pandemia, lo que no ocurría desde el año 1968.
\end{abstract}

Existen muchos aspectos a considerar para enfrentarnos a esta enfermedad, aunque hay dos estrategias que pueden ocupar un lugar destacado en esta lucha. Por una parte, el manejo adecuado de la información y su transmisión a la población general. Otra actuación a destacar se refiere a la utilización de un sistema adecuado de clasificación o triage de los posibles infectados por el virus de la gripe.

En cuanto al primer elemento, podemos destacar que desde la aparición de los primeros casos de gripe en Méjico hasta hoy únicamente han pasado 6 meses, sin embargo, la amplia cobertura informativa desplegada ha permitido difundir la mayor parte del conocimiento generado sobre este tema. Los diferentes organismos nacionales e internacionales han facilitado el flujo de información desde los primeros días.

No nos olvidamos en ningún momento de la escasa información o de la falta de evidencias en diferentes aspectos relacionados con la gripe, sin embargo, sí estamos seguros de la importancia de difundir y facilitar la recepción del conocimiento generado. En este sentido, existen dudas relacionadas con el tratamiento, la vacunación y con la actuación en diferentes grupos de edad. No obstante, ese escaso tiempo transcurrido desde el inicio de la pandemia puede explicar la presencia provisional de esos interrogantes. Se trata, por tanto, de resaltar lo que conocemos y poner los medios necesarios para facilitar el flujo de esa información.

En nuestro país, el Ministerio de Sanidad y Política Social colabora de forma permanente en la difusión de las respuestas a cada de una de las cuestiones planteadas desde las primeras semanas del brote. Se presenta toda la información sobre la gripe A en diferentes apartados: informe de situación, comunicados del Ministerio de Sanidad y Política Social, preguntas y respuestas más frecuentes, recomendaciones para prevenir la gripe e información dirigida a profesionales (guías, protocolos e informes técnicos). La colaboración de las sociedades científicas como la Sociedad Española de Medicina de Familia y Comunitaria (semFYC) está presente en todo momento.

Se informa a profesionales sanitarios y a la población general sobre lo que es la gripe, el agente causal, el mecanismo de transmisión, la prevención y los síntomas de la enfermedad. Los diferentes organismos internacionales (OMS, CDC) y nacionales, como el Ministerio, las Comunidades Autónomas y las sociedades científicas, aportan y reciben, continuamente, datos y conocimientos que les permiten elaborar recomendaciones sobre la actuación frente a la gripe $A$.

Las definiciones de casos probables, confirmados o en investigación han cambiado a medida que se conocían más detalles sobre la enfermedad y el virus causal, por lo que se invita a consultar de forma continua la Web de la Comunidad Autónoma o del Ministerio de Sanidad. La Sociedad Española de Medicina de Familia y Comunitaria (semFYC) ha elaborado un Documento de Recomendaciones para profesionales sobre el manejo diagnóstico y terapéutico de infección por el virus de la influenza tipo A (H1N1) y la organización de la asistencia. En este documento se define como caso sospechoso de gripe $\mathrm{A}$ en nuestro medio a cualquier persona con fiebre superior a $38^{\circ} \mathrm{C}$, en ausencia de otra causa conocida y al menos dos signos o síntomas de infección respiratoria aguda: tos, rinorrea, dolor de garganta, dificultad respiratoria, cefalea, mialgia o malestar general. Se refuerza la sospecha si existe como antecedente el contacto estrecho con un caso de gripe. Pueden ir acompañados de diarrea y vómitos. La presencia de neumonía es criterio de caso sospechoso.

Se ha observado que los niveles de infección son más altos en los niños, adolescentes y adultos jóvenes entre 20-40 años. Nos afecta un virus de escasa virulencia, que provoca una infección de curso autolimitado y resolución espontánea completa aproximadamente en una semana en la mayoría de los pacientes sin factores de riesgo. Actualmente los casos más graves y las muertes han afectado a los adultos menores de 50 años, mien- 
tras que han sido poco frecuentes los casos fatales en las personas mayores. Las complicaciones más graves se han producido en aquellos pacientes que presentaban factores de riesgo.

Las instituciones sanitarias y las sociedades científicas han entendido que todo el conocimiento generado podría perder utilidad si no es transmitido de forma adecuada a cada uno de los agentes implicados en la pandemia. Por este motivo, han colaborado en la elaboración y difusión de las recomendaciones dirigidas a la población general sobre las medidas para prevenir la gripe en su domicilio (forma correcta de realizar el lavado de manos, el uso adecuado de mascarillas), en el colegio y en el medio laboral. También se han dado pautas higiénico-sanitarias para enfermos de gripe y sus cuidadores. En este mismo sentido, se recomienda facilitar a toda la población la información necesaria para la utilización óptima de los recursos sanitarios disponibles. Esta información permitirá a los pacientes participar de una forma más activa en su propia salud. Si un paciente con síntomas de gripe no presenta criterios de gravedad ni pertenece a ningún grupo de riesgo puede seguir las recomendaciones que corresponden a estos casos sin necesidad de consultar a su médico. Las ventajas derivadas parecen claras, tanto para el sistema sanitario como para el propio paciente, en el que se evitarán molestias innecesarias.

A continuación, nos referimos al otro elemento que desempeña un papel destacado en la respuesta a una situación de pandemia. La elevada frecuentación que caracteriza a la Atención Primaria hace que las situaciones de alta demanda asistencial no sean desconocidas para nuestros profesionales. Anualmente experimentamos las consecuencias de las epidemias de gripe común, sin embargo la aparición de una gran pandemia nos impulsa a tomar medidas especiales para ofrecer una respuesta. Es prioritario desarrollar, desde las fases previas de la pandemia, una correcta planificación y coordinación que responda al exceso de demanda. Una de las medidas organizativas que se proponen en estos casos es la instauración de sistemas de clasificación de pacientes que permitan optimizar la utilización de los recursos asistenciales. Esta clasificación o "triage" es una forma de organizar los distintos niveles asistenciales para facilitar el proceso de evaluación clínica ante la demanda de asistencia y la clasificación de los pacientes antes de la valoración diagnóstica y terapéutica completa. Es un método a utilizar en situaciones de saturación de los servicios sanitarios y disminución de los recursos. Permite clasificar a los pacientes empleando poco tiempo y establece prioridades de actuación según los niveles de gravedad.
El triage debe señalar y definir las estrategias necesarias para la clasificación de los pacientes en este contexto de epidemia de gripe. Se realiza siguiendo un protocolo estructurado y sistemático. Se deben emplear preguntas específicas encaminadas a establecer la sospecha inmediata de caso. La rápida identificación de los casos sospechosos evitará la exposición de pacientes con enfermedades comunes a la infección. El interrogatorio contemplará una serie de hallazgos que van a definir los grados de prioridad de asistencia, en función de los síntomas y signos de alarma, gravedad, la afectación del estado general y la existencia de enfermedades crónicas.

Mediante un triage adecuado será posible identificar a los sujetos sospechosos de padecer gripe pandémica, y separarlos del resto de las personas para disminuir el riesgo de transmisión de la enfermedad e identificar el tipo de atención que requieren. A partir de la información obtenida mediante el interrogatorio, el protocolo debe recomendar la respuesta más adecuada, los recursos que se deben asignar o la posible necesidad de una valoración posterior más detenida.

Por otra parte, debemos tener en cuenta el adecuado aislamiento de los enfermos para evitar el contagio al resto de pacientes y al personal sanitario. Esta cuestión puede resultar, en algunos casos, complicada por la estructura arquitectónica de nuestros centros, pero de vital importancia para evitar la propagación de la enfermedad. La atención telefónica puede considerarse como una posible solución a este problema e incluir un triage telefónico puede ser una forma muy recomendable de asistencia en una situación de pandemia.

En resumen, la transmisión de toda la información necesaria a las personas que utilizarán los servicios de salud permitirá optimizar los recursos ofertados. El conocimiento de la existencia de un sistema que permite clasificar la demanda y resolverla de forma rápida es esencial para que esta estrategia organizativa muestre su eficacia. En el caso concreto del triage, la correcta implantación del mismo y su éxito dependen del grado de conocimiento de la población sobre la forma de acceder al mismo. Probablemente, el aumento de la demanda, que acompaña a la aparición de una pandemia de gripe, justifica los esfuerzos necesarios para lograr que ese conocimiento llegue a cada uno de los agentes implicados.

Ignacio Párraga Martínez Médico de Familia

Unidad de Investigación Gerencia de Atención Primaria de Albacete 


\section{BIBLIOGRAFÍA}

- Documentación sobre gripe A de la Consejería de Sanidad de Castilla-La Mancha. Vigilancia de la Gripe. Disponible en http:// sescam.jccm.es/web1/profHome.do?main=/gripe/gripe.html

- Página de inicio del Ministerio de Sanidad y Política social. Disponible en http://www.msps.es/

- Documentación sobre la gripe A H1A1 de la OMS. Disponibles en español e ingles en: http://www.who.int/csr/disease/swineflu/ es/index.html y http://www.who.int/csr/disease/swineflu/updates/en/index.html.

- Centro Cochrane Iberoamericano. Prevención y tratamiento de

la gripe. Disponible en http://www.cochrane.es/?q=es/node/335

- Saldaña Díaz O, Carrión Méndez CA, Díaz Soto E. Epidemia de gripe nueva $A(\mathrm{H} 1 \mathrm{~N} 1)$ : la visión desde un servicio de urgencias de México DF. Emergencias 2009; 21:224-7.

- Plan Regional de Actuaciones Frente a una Pandemia de Gripe de Castilla-La Mancha. Recomendaciones para la clasificación de pacientes que demandan asistencia en el contexto de una pandemia de gripe por Nuevo Virus A/H1N1. Dirección General de Salud Pública; 2009.

- Recomendaciones para profesionales sobre el manejo diagnóstico y terapéutico de infección por el virus de la influenza tipo A (H1N1) y la organización de la asistencia sociedad Española de Medicina de Familia y Comunitaria (semFYC). Grupo de Trabajo de Enfermedades Infecciosas; 2009. 